\title{
A Study on the Improvement of Safety Management System for ATO
}

\section{- Base on the Aviation Safety Voluntary Reporting System -}

\author{
Jin-Tae Kim", Gun Young Lee ${ }^{* \text {, }}$, Jin-Kook Choi ${ }^{\text {*Now }}$
}

\begin{abstract}
As all flight training institutions in Korea were approved by the Ministry of Land, Infrastructure and Transport (MOLIT) as aviation training organizations (ATO), safety management based on the Aviation Safety Management System (SMS) became mandatory. However, even though safety management using SMS has become mandatory, the performance of aviation safety voluntary report, which is the core of the system, remains low compared to other countries. The current address of SMS, a ATO, is like a watermill without water. The present study is to find out why voluntary aviation safety reports, which is equivalent to water from waterwheel, is underperforming and to suggest ways to revitalize it.
\end{abstract}

Key Words : Approved Training Organization(ATO, 전문교육기관), SMS(항공안전관리시스템), Aviation Safety Voluntary Report(항공안전자율보고), Aviation Safety(항공안전), Safety Management (안전관리)

\section{INTRODUCTION}

To identify unanticipated risk factors, aviation safety voluntary report is essential to the effective operation of aviation Safety Management System (SMS). Through the aviation safety voluntary report "Entering Downwind into the Visual Flight Rules (VFR) Route from the Opposite Direction" submitted to the flight training institute at Uljin Airport, the control center revised the standard operational procedure to use, if possible, a straight-in approach

Received: 04. Dec. 2020, Revised: 09. Dec. 2020,

Accepted: 14. Dec. 2020

* Korea National University of Transportation

** Professor, Korea National University of Transportation

*** Professor, Korea National University of Transportation Corresponding Author E-mail : safeskyleader@gmail.com Corresponding Author address : 50 Daehak-ro, Chungiusi, Chungbuk when entering the VFR route instead of making a steep turn for entrance in order to prevent reverse entry into Uljin Airport's VFR route by training aircrafts.

The above demonstrates that aviation safety voluntary report system is a vital factor for preventing accidents. However, evident from the reception status of aviation safety voluntary reports (Table 2), the settlement of the system trails behind compared to those of developed countries. In particular, track records of Approved Training Organizations (ATO) are significantly lower than those of others in the aviation industry. Accordingly, this study interviewed safety officers with at least five years at ATO work experience, flight instructors, maintenance engineers and students to verify the system and aims to provide a realistic plan of improvement. 


\section{RESEARCH}

\subsection{Approved training organization}

Following the revised Aviation Act of December 14, 1991, the revised enforcement ordinances of Aviation Act of August, 17, 1992, and the revised enforcement regulations of Aviation Act of February 13, 1993, the system of Approved Training Organizations was established in Korea. In order to elevate the general competitiveness of the aviation industry and intensively cultivate aviation workers, who are expected to be in great shortage, the system was established to fit domestic circumstances while observing the criteria as stipulated in Annex 1 of International Civil Aviation Organization (ICAO).

To be designated as an ATO, application and on-site reviews are conducted for an organization to examine whether its aviation personnel educational courses and methods, status of instructors, and facilities and equipment comply with the standards stipulated in the above bulletin.

\subsubsection{Status of ATOs in Korea (pilot)}

As shown in Table 1, there are a total of 23 ATOs for pilot training in Korea; twelve are universities, such as Korea Aerospace University and Korea National University of Transportation, one manufacturer, Korea Aerospace Industries, Ltd, seven airplane using businesses, like Sunny Air(Hong, 2020) and three military organizations.

\subsection{Aviation safety management system}

The Aviation Safety Management System aims

Table 1. Approved training organization status (Hong, 2020)

\begin{tabular}{c|c|c|c|c}
\hline $\begin{array}{c}\text { Universit- } \\
\text { ies }\end{array}$ & $\begin{array}{c}\text { Manufact- } \\
\text { urer }\end{array}$ & $\begin{array}{c}\text { Airplane } \\
\text { using } \\
\text { business }\end{array}$ & $\begin{array}{c}\text { Military } \\
\text { Organiz- } \\
\text { ations }\end{array}$ & Total \\
\hline 12 & 1 & 7 & 3 & 23 \\
\hline
\end{tabular}

to limit risks of damage or loss to an appropriate level. Since human and organizational factors have controls over risks, clear, systematic and preemptive safety management activities are possible through regular communication between the organization and the safety committee, and safety awareness of all members, based on the selection of suitable managers and safety policies and goals set by the head of organization (Yun, 2013).

\subsubsection{Collection of safety data and information}

All organizations must decide upon the safety data and information to collect in order to support safety performance management process and to make safety decisions. Verifying and collecting safety data must meet the demands of the organization that should effectively manage safety. In some cases, it emphasizes on additional safety data so as to better evaluate the effects of safety risk management process (levels of risk and severity) and identify relevant risks. Likewise, safety performance management process may stress on the need for additional information for a more comprehensive understanding of a particular safety issue and/or the establishment or improvement of safety performance indicators (Lee, 2019).

\subsubsection{Methods for collecting safety data}

Depending on the size of an organization, the 23 ATOs (pilot) in Korea are run by 10 to 30 employees, who are flight instructors, aircraft maintenance instructors and operational management instructors, while also taking on various administrative tasks that sustain the organization. Unlike large airlines, these ATOs are not equipped with professional manpower that specializes in safety tasks, and thus, experience much difficulty in collecting safety data, which is critical to preventing accidents.

Methods of data collection used at ATOs are investigations for accidents and serious acci- 
dents, aviation safety voluntary report, line operations safety audit (LOSA), flight data log (FDL), voluntary and mandatory safety report system, and safety patrol.

\subsection{Aviation safety voluntary report system}

It is possible to prevent flight accidents and secure safety by discovering potential hazards, identifying problems and establishing solutions. The aviation safety voluntary report system is one that guarantees pardon for mistakes that do cause grave problems, while protecting the reporter's identity so that matters of safety issues can be disclosed without hesitation. In Annex 19 of ICAO, the implementation of aviation safety voluntary report system was amended from "recommended" to "mandatory enforcement" for all members of ICAO.

Table 2 summarizes the number of aviation safety voluntary reports submitted to Korea Transportation Safety Authority between 2015 and July, 2020. A total of 791 reports from pilots, air traffic controls, cabin crews, maintenance engineers and others were submitted during this period.

Table 3 shows the number of reports received by NASA in 2019 alone, where a total of 5,997 reports were made from Part 91 (civil aircrafts), Part 121 (air carriers), and Part 135 (commercial, non-scheduled aircraft operations).

Compared to the figures of the US, Korea's number of aviation safety voluntary reports is low in relation to the size of its aviation industry. This is attributable to the culture of Korean pilots unwilling to disclose their mistakes, lack of publicity, and absence of trust related to punishment.

\subsection{ATO interviews on aviation safety voluntary report}

A total of 20 personnel at Muan International Airport's ATO were interviewed on aviation
Table 2. Aviation safety voluntary reports reception status (Kim, 2020)

(Number of reports)

\begin{tabular}{|c|c|c|c|c|c|c|}
\hline Year & Pilot & ATC & Cabin & \begin{tabular}{|} 
Main- \\
tenance
\end{tabular} & Etc. & Total \\
\hline 2015 & 67 & 23 & 0 & 2 & 58 & 150 \\
\hline 216 & 114 & 11 & 0 & 0 & 48 & 173 \\
\hline 217 & 92 & 13 & 1 & 1 & 30 & 137 \\
\hline 218 & 67 & 16 & 3 & 1 & 18 & 105 \\
\hline 219 & 94 & 50 & 0 & 2 & 17 & 163 \\
\hline $\begin{array}{l}220 \\
\text { July }\end{array}$ & 38 & 16 & 0 & 1 & 8 & 63 \\
\hline Total & 472 & 129 & 4 & 7 & 179 & 791 \\
\hline
\end{tabular}

Table 3. US aviation database online (NASA, 2020)

(Number of reports)

\begin{tabular}{c|c|c|c|c}
\hline Year & Part 91 & Part 121 & Part 135 & Total \\
\hline 2019 & 1,456 & 4,251 & 290 & 5,997 \\
\hline
\end{tabular}

safety voluntary report, five from each division of safety officers, flight instructors, maintenance engineers and students. There are three categories of questions, and a total of 10 questions on aviation safety voluntary report, SMS, and punishment and responsibility related to accident reports. Interviewees were asked to rate the questions on a five-point scale (1: do not know; 3: somewhat know; 5: clearly know).

According to survey results, as shown in Table 4, responses of 1 (do not know) and 3 (somewhat know) accounted for 155 choices out of the total 200, composing $77 \%$ of all choices.

Analysis of survey results demonstrated that while safety officers were aware of aviation safety voluntary report and SMS, other personnel either lacked interest or knowledge of it. The fact that there are numerous aviation personnel who do not know aviation safety voluntary report and its submission method has been identified as the problem that needs to be 
Table 4. The number of people studied

(Number of persons)

\begin{tabular}{|c|c|c|c|c|c|c|}
\hline \multirow{2}{*}{ Category } & \multirow{2}{*}{ Questions } & \multicolumn{5}{|c|}{ Scale } \\
\hline & & 1 & 2 & 3 & 4 & 5 \\
\hline \multirow{3}{*}{$\begin{array}{l}\text { Aviation } \\
\text { safety } \\
\text { voluntary } \\
\text { reports }\end{array}$} & $\begin{array}{l}\text { Cognitive } \\
\text { status }\end{array}$ & 10 & & 5 & 3 & 2 \\
\hline & $\begin{array}{l}\text { Reporting } \\
\text { system }\end{array}$ & 10 & & 5 & 4 & 1 \\
\hline & Rewards & 12 & 1 & & 1 & 6 \\
\hline \multirow{4}{*}{$\begin{array}{c}\text { SMS } \\
\text { (Safety } \\
\text { manage- } \\
\text { ment } \\
\text { system) }\end{array}$} & $\begin{array}{l}\text { Cognitive } \\
\text { status }\end{array}$ & & & 13 & 2 & 5 \\
\hline & Components & 3 & 10 & 2 & & 5 \\
\hline & $\begin{array}{l}\text { Relationship } \\
\text { with aviation } \\
\text { safety } \\
\text { voluntary } \\
\text { report }\end{array}$ & 15 & & 4 & 1 & \\
\hline & $\begin{array}{l}\text { Operation- } \\
\text { related }\end{array}$ & 13 & & 2 & & 5 \\
\hline \multirow{3}{*}{$\begin{array}{l}\text { Accident } \\
\text { reports }\end{array}$} & $\begin{array}{l}\text { Accident / } \\
\text { incident } \\
\text { information } \\
\text { sharing }\end{array}$ & 15 & & 1 & 1 & 3 \\
\hline & $\begin{array}{l}\text { Education } \\
\text { status }\end{array}$ & 13 & & 3 & & 4 \\
\hline & $\begin{array}{l}\text { Punishment } \\
\text { Related }\end{array}$ & 18 & & & & 2 \\
\hline
\end{tabular}

addressed. It has also been made aware that there was confusion on the extent of application of non-punitive principle, and that there were limited methods of verifying safety-related information. There is a lack of awareness for sharing safety information, and the reality is that $\mathrm{pu}^{-}$ nishment is generally carried out as a method of recurrence prevention.

On the other hand, it was found that the performance of aviation safety voluntary report is closely related to a reward system. The consensus was that it is difficult to improve the performance of aviation safety voluntary report through the existing reward system. It was concluded that the implementation of a reward system relevant to one's personal identity, such as granting extra points when hired at an air transport company, could actively encourage participation in aviation safety voluntary report system.

\section{CONCLUSION}

The Ministry of Land, Infrastructure, and Transport of Korea is managing safety through the implementation of SMS, which appointed all aviation institutes in the country as ATOs, as a measure to ensure a systematic aviation education and aviation safety. Despite such efforts, there are constraints to effectively utilizing SMS at ATOs that have a limited number of officers.

The purpose of this study is to manage risk, the essence of SMS, by collecting data related to aviation safety through aviation safety voluntary report. It verified the state of aviation safety voluntary report at ATOs and reached the below conclusion.

First, there is a lack of information on aviation safety voluntary report, and airline personnel only report an issue when related to punishment.

Second, they do not recognize the necessity of aviation safety voluntary report.

Third, there are limited methods to share information related to aviation safety.

The limitation of this study is that considering the uniqueness of the sample, the ATO at Muan International Airport, the number is quite small. It is possible to obtain a more accurate data by continuously accumulating it to increase the number of samples in the future. Furthermore, efforts should be made by aviation industry employees to contribute to aviation safety by entering and sharing data themselves. Aviation safety is not the responsibility of only chief management or safety officers. As the first step to preventing accidents, aviation safety will be realized when all aviation personnel recognize and promote safety aware- 
ness, upon which voluntary safety reports will take place.

\section{Acknowledgments}

This paper is a modified version of a published manuscript submitted to the 2020 Fall Conference of the Korean Society for Aviation and Aeronautics.

\section{References}

1. Hong, B. P., "The Status of ATO", 2020, URL: http://www.molit.go.kr/USR/policyData/m_34 681/dtl.jsp?id=4473
2. Yun Y. J., "Air safety management system research and development", Korea Civil Aviation Association, Aviation Promotion 60, 2013, pp. 75.

3. Lee G. Y., "Safety Management System," Booknet Publishing Company, Seoul, 2019, pp. 94.

4. Kim K. J., "Aviation safety voluntary reporting system”, 2020 SMS Theory and Practical Course, Korea Transportation Safety Authority, 2020, p. 217.

5. NASA, "ASRS Data Base", https://akama.arc. nasa.gov/ASRSDBOnline/QueryWizard_Filter. aspx 